\title{
Article
}

\section{Using High-Power UV-LED to Accelerate a Decatungstate-Anion-Catalyzed Reaction: A Model Study for the Quick Oxidation of Benzyl Alcohol to Benzoic Acid Using Molecular Oxygen}

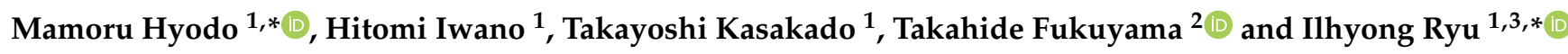 \\ 1 Organization for Research Promotion, Osaka Prefecture University, Sakai, Osaka 599-8531, Japan; \\ iwano@c.s.osakafu-u.ac.jp (H.I.); t_kasakado@c.s.osakafu-u.ac.jp (T.K.) \\ 2 Department of Chemistry, Osaka Prefecture University, Sakai, Osaka 599-8531, Japan; \\ fukuyama@c.s.osakafu-u.ac.jp \\ 3 Department of Applied Chemistry, National Yang Ming Chiao Tung University (NYCU), \\ Hsinchu 30010, Taiwan \\ * Correspondence: hyodo_mam@c.s.osakafu-u.ac.jp (M.H.); ryu@c.s.osakafu-u.ac.jp (I.R.)
}

check for updates

Citation: Hyodo, M.; Iwano, H.; Kasakado, T.; Fukuyama, T.; Ryu, I. Using High-Power UV-LED to Accelerate a Decatungstate-Anion-Catalyzed Reaction: A Model Study for the Quick Oxidation of Benzyl Alcohol to Benzoic Acid Using Molecular Oxygen. Micromachines 2021, 12, 1307. https://doi.org/10.3390/mi12111307

Academic Editor: Yangcheng Lu

Received: 14 July 2021

Accepted: 22 October 2021

Published: 25 October 2021

Publisher's Note: MDPI stays neutral with regard to jurisdictional claims in published maps and institutional affiliations.

Copyright: (C) 2021 by the authors Licensee MDPI, Basel, Switzerland. This article is an open access article distributed under the terms and conditions of the Creative Commons Attribution (CC BY) license (https:/ / creativecommons.org/licenses/by/ $4.0 /)$.

\begin{abstract}
High-power UV-LED irradiation (365 nm) effectively accelerated the decatungstate-anioncatalyzed oxidation of benzyl alcohol 1 to benzoic acid 3 via benzaldehyde 2 . As the power of the UV-LED light increased, both the selectivity and yield of benzoic acid also increased. The reaction was finished within $1 \mathrm{~h}$ to give 3 in a 93\% yield using $2 \mathrm{~mol} \%$ of decatungstate anion catalyst. The combination of a flow photoreactor and high-power irradiation accelerated the oxidation reaction to an interval of only a few minutes.
\end{abstract}

Keywords: molecular oxygen; oxidation; high power UV-LED; benzyl alcohol; benzoic acid

\section{Introduction}

Decatungstate anion $\left(\mathrm{W}_{10} \mathrm{O}_{32}{ }^{4-}\right)$, when photo-excited, catalyzes $\mathrm{C}\left(\mathrm{sp}^{3}\right)$-H functionalization via hydrogen atom transfer (HAT) to create alkyl radicals [1-5]. When molecular oxygen or oxidizing reagents are present, decatungstate catalyzes the oxidation of $\mathrm{C}\left(\mathrm{sp}^{3}\right)-\mathrm{H}$ bonds [6-11]. The UV-VIS spectrum of decatungstate anions [12] is featured in Figure 1. To accomplish photo-irradiation, a xenon lamp is frequently used. Recent work has shown, however, that a low-power blacklight $(15 \mathrm{~W}, 352 \mathrm{~nm})$ some other light sources around $390 \mathrm{~nm}$ can also affect C-H alkylation [13]. In the pursuit of improved photo-efficiency, decatungstate-catalyzed reactions were conducted in flow using thin microchannels, which contributed to shortening of the irradiation time [14-17].

Despite much work dealing with photocatalytic oxidation using decatungstate anion as the catalyst, only a few studies have focused on accelerating the reaction via intense irradiation from a light source, ever since the early efforts by Hill [18-20]. That situation motivated us to investigate how the decatungstate-anion-catalyzed oxidation would be affected when powered by photo-irradiation equipment. We focused on catalytic oxidation using a decatungstate anion and molecular oxygen [21-25] under varied photo-irradiation conditions. For this study, we used a Photo System U-1, which is composed of $365 \mathrm{~nm}$ UV-LED light (Kyocera G-5A), a controller, and a power supply, which provides irradiation power that is adjustable in a range from 60 to $480 \mathrm{~W}$. Scheme 1 illustrates the model oxidation reaction of $\mathbf{1}$, which leads to benzoic acid $\mathbf{3}$ via benzaldehyde $\mathbf{2}$, as well as the proposed mechanism. In this reaction, hydrogen atom transfer (HAT) by photo-excited decatungstate ion triggers the oxidation. Benzyl alcohol has only one type of $\mathrm{C}\left(\mathrm{sp}^{3}\right)-\mathrm{H}$ bond available for the HAT process and is frequently used for oxidation as a model compound [26-28]. Accumulated $\mathrm{H}^{+} \mathrm{W}_{10} \mathrm{O}_{32}{ }^{5-}$ is oxidized by molecular oxygen to recover 
$\mathrm{W}_{10} \mathrm{O}_{32}{ }^{4-}$. Pleasingly, we were able to find that the reaction was complete within $1 \mathrm{~h}$ when high-power irradiation by $480 \mathrm{~W}$-irradiation was employed, giving benzoic acid 3 in both excellent selectivity and yield.

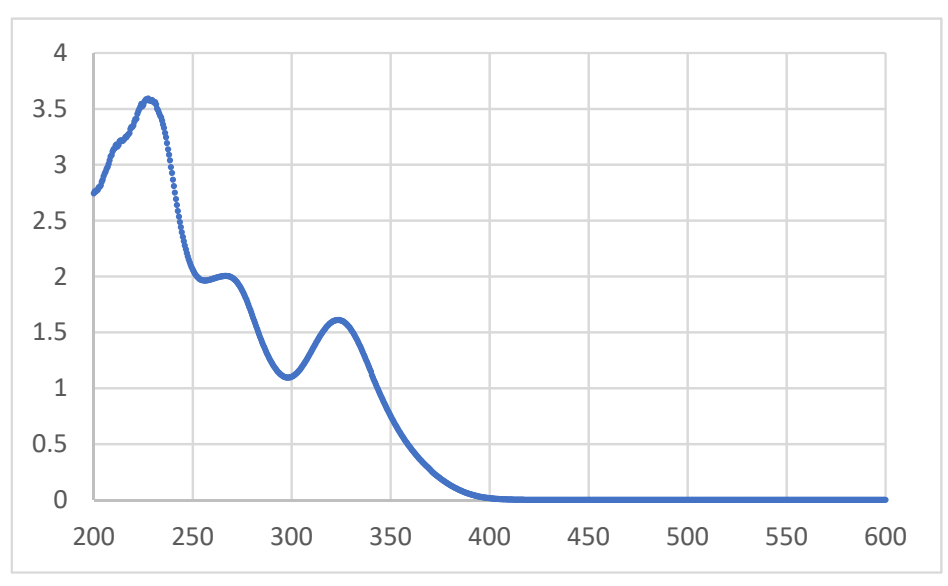

Figure 1. UV-VIS Spectrum of decatungstate anion in acetonitrile $\left(1.1 \times 10^{-4} \mathrm{M}\right.$, TBADT $\left.\left(\mathrm{Bu}_{4} \mathrm{~N}\right)_{4} \mathrm{~W}_{10} \mathrm{O}_{32}\right)$.
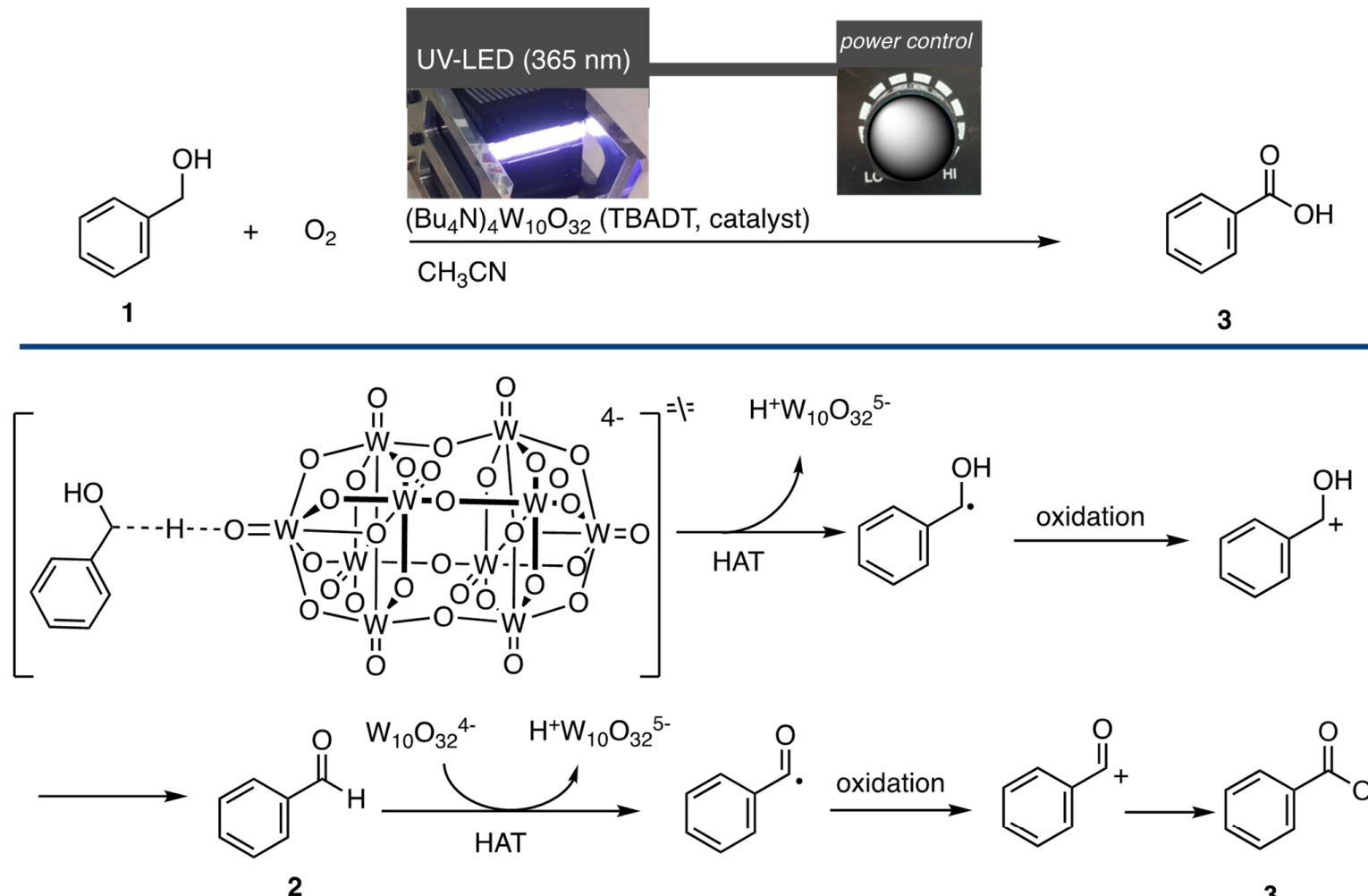<smiles>O=Cc1ccccc1</smiles><smiles>O=Cc1ccccc1</smiles><smiles>CCc1ccc(C(=O)O)cc1</smiles>

3

catalyst regeneration

$$
\mathrm{H}^{+} \mathrm{W}_{10} \mathrm{O}_{32}{ }^{5-} \stackrel{\mathrm{O}_{2}}{\stackrel{\text { oxidation }}{\longrightarrow}} \mathrm{W}_{10} \mathrm{O}_{32}^{4-}
$$

Scheme 1. Improving the catalytic efficiency of decatungstate-anion-catalyzed oxidation using molecular oxygen via high-power UV-LED. 


\section{Experimental}

\subsection{General Information}

${ }^{1} \mathrm{H}$ NMR spectra were recorded using Spinsolve Ultra $60(60 \mathrm{MHz})$ spectrometers in $\mathrm{CD}_{3} \mathrm{CN}$, which were referenced at $0.00 \mathrm{ppm}$ for tetramethylsilane. Chemical shifts are reported in parts per million $(\delta)$. Splitting patterns are indicated as follows: br, broad; $s$, singlet; $\mathrm{d}$, doublet; $\mathrm{t}$, triplet;, $\mathrm{m}$, multiplet. GC analysis was performed on a Shimadzu GC2014 instrument equipped with an FID detector using a J\&W Scientific DB-1 column under the following conditions: initial oven temperature was held at $50^{\circ} \mathrm{C}$ for $5 \mathrm{~min}$; the first ramp was $10^{\circ} \mathrm{C} / \mathrm{min}$ to $250^{\circ} \mathrm{C}$, which was held for $5 \mathrm{~min}$. UV-visible absorption spectra were measured by V-630 Spectrometer (JASCO). The detector used for the measurement of optical density was a UV power meter C9563_H9958-01 purchased from Hamamatsu Photonics. Benzyl alcohol (1), sodium tungstate, and tetrabutylammonium bromide were purchased from Nacalai Tesque. TBADT was prepared according to the reported procedure [3]. The blacklight was purchased from Toshiba (Tokyo, Japan). The photo system UV-LED (MiChS UV-LED-S equipped with Kyocera G5A (365 nm, 60-480 W)), the MiChS L-1 flow system, and T-shape mixer MiChS $\alpha 400$ were purchased from MiChS Inc (Osaka, Japan): http:/ / www.michs.jp (accessed on 24 October 2021).

\subsection{Typical Procedure for the Oxidation of Benzyl Alcohol 1}

Benzyl alcohol $1(0.25 \mathrm{mmol}, 25 \mathrm{mg})$ and TBADT $(0.005 \mathrm{mmol}, 15 \mathrm{mg})$ were added to a $15 \mathrm{~mL}$ glass tube along with a solvent $\left(\mathrm{CH}_{3} \mathrm{CN}, 0.6 \mathrm{~mL}\right)$ and equipped with an $\mathrm{O}_{2}$ balloon. The mixture was stirred at room temperature and irradiated either by a blacklight or by a UV-LED. After the reaction, $\mathrm{Et}_{2} \mathrm{O}$ was added to the reaction mixture and filtered to remove the precipitated TBADT. An aliquot of the solution then was applied to GC analysis.

\subsection{The Procedure for the Isolation of Benzoic Acid 3}

Benzyl alcohol 1 (1.0 mmol, $108 \mathrm{mg})$ and TBADT (0.02 mmol, $60 \mathrm{mg})$ were added to a $50 \mathrm{~mL}$ glass tube along with a solvent $\left(\mathrm{CH}_{3} \mathrm{CN}, 2.4 \mathrm{~mL}\right)$ and equipped with an $\mathrm{O}_{2}$ balloon. The mixture was stirred at room temperature for $30 \mathrm{~min}$ and irradiated by the UV-LED $(365 \mathrm{~nm}, 480 \mathrm{~W})$. After the reaction, $\mathrm{Et}_{2} \mathrm{O}$ was added to the reaction mixture and filtered to remove the precipitated TBADT and concentrated to dryness. The crude product (122 mg) was recrystallized from $\mathrm{H}_{2} \mathrm{O}$ to give a white crystalline of benzoic acid 3 (100 mg, $81 \%$ yield).

\subsection{The Procedure for the Flow Oxidation of Benzyl Alcohol 1}

The flow oxidation reaction was carried out using a MiChS UV-LED-S photo-system and MiChS L-1 photo-microreactor, which had a single-lane channel $(2 \mathrm{~mm}$ in width, $1 \mathrm{~mm}$ in depth, $3 \mathrm{~m}$ in length, total volume $6 \mathrm{~mL}$ ) covered with quartz. This photoreactor was irradiated by UV-LED $(365 \mathrm{~nm}, 480 \mathrm{~W})$. An acetonitrile solution containing benzyl alcohol $(55 \mathrm{mM})$ and TBADT $(1.1 \mathrm{mM})$ was prepared and placed in a syringe (SGE syringe, Trajan Scientific). Oxygen gas was also taken in a syringe. These solutions were pumped into a MiChS L-1 photo-microreactor through a MiChS $\alpha 400$ micromixer using a syringe pump at rates of $0.1 \mathrm{~mL} / \mathrm{min}$ (reaction solution) and $1.1 \mathrm{~mL} / \mathrm{min}$ (oxygen), respectively (residence time: $5 \mathrm{~min}$ ). The reaction mixture eluted from the outlet was discarded for the first $15 \mathrm{~min}$ and the subsequent portion was collected for $15 \mathrm{~min}$. The collected reaction mixture was treated with $\mathrm{Et}_{2} \mathrm{O}$, filtered via a celite pad, and subjected to GC analysis to determine the yield.

\section{Results and Discussion}

The photo-reaction setup is featured in Figure 2. A test tube reactor with a screw cap (diameter $15 \mathrm{~mm}$, length $10 \mathrm{~cm}$ ) was used for the photo reaction. A low-power blacklight (352 nm, $15 \mathrm{~W}$ ) was acquired from Toshiba (Figure 2a). A high-power UV-LED system (365 nm, (Figure 2b) was acquired from MiChS. 
a)

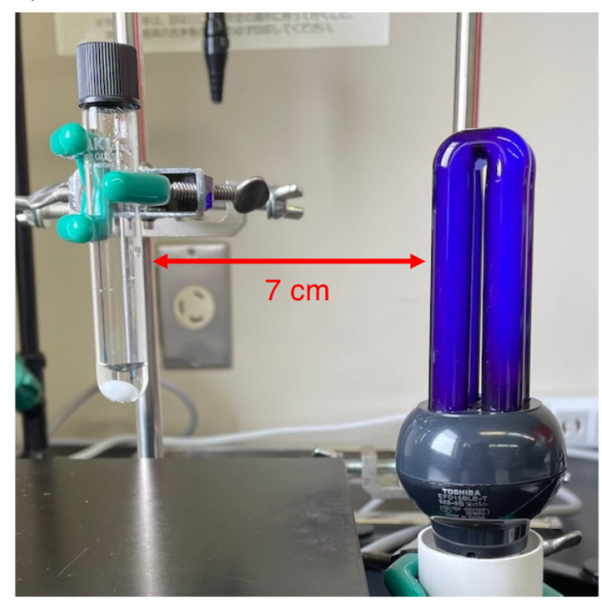

b)

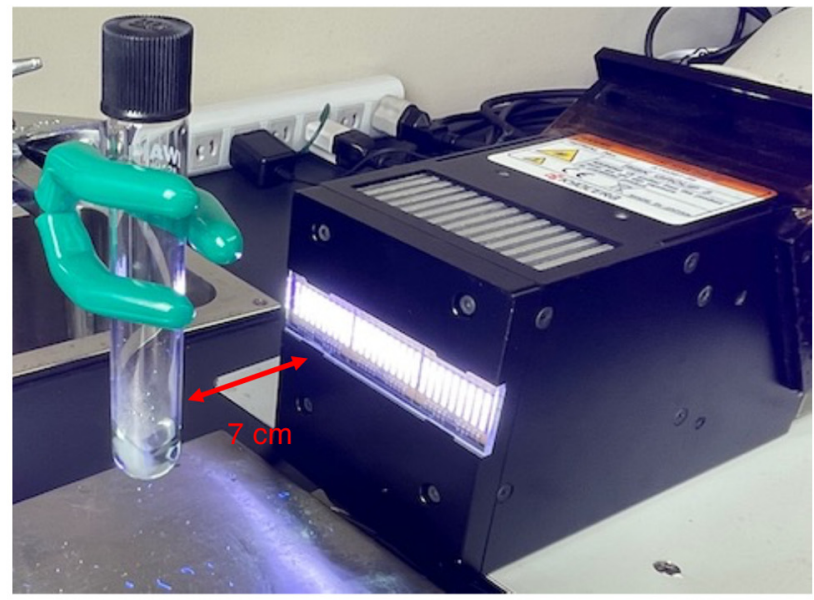

Figure 2. Photo-irradiation setup: (a) test tube reactor irradiated by a low-power blacklight (352 nm); (b) test tube reactor irradiated by a high-power UV-LED-S (365 nm).

The oxidation of benzyl alcohol $1(0.25 \mathrm{mmol})$ was carried out in the presence of a catalytic amount of tetrabutylammonium decatungstate (TBADT, $15 \mathrm{mg}, 2 \mathrm{~mol} \%$ ) in acetonitrile $(0.6 \mathrm{~mL})$ under atmospheric pressure of $\mathrm{O}_{2}$. The reaction products were analyzed by GC and the results are summarized in Table 1 . We started with an oxidation reaction of 1 using a test tube (Pyrex, diameter size: $15 \mathrm{~mm}$ ) and a blacklight. The reaction using a blacklight was sluggish, and after $1 \mathrm{~h}$, it gave only a $21 \%$ yield of benzaldehyde 2 and a trace amount of benzoic acid 3 (Table 1, entry 1). A similar reaction was carried out for $6 \mathrm{~h}$, which resulted in $49 \%$ yield of benzaldehyde and $22 \%$ yield of benzoic acid (Table 1, entry 2). The overnight reaction ( $20 \mathrm{~h}$ ) gave benzoic acid 3 as a principal product (Table 1, entry 3). Then, we switched to UV-LED, for which we applied 120, 300, and $480 \mathrm{~W}$ irradiation for the model reaction. After $1 \mathrm{~h}$ of UV-LED irradiation at $120 \mathrm{~W}$, the reaction proceeded much more efficiently than the blacklight irradiation had and yielded $38 \%$ of benzaldehyde and $54 \%$ of benzoic acid (Table 1 , entry 4 ). When we employed irradiation at $300 \mathrm{~W}$, benzyl alcohol 1 was completely consumed after $1 \mathrm{~h}$ and a 31/69 mixture of benzaldehyde 2 and benzoic acid 3 was formed (Table 1, entry 5). Gratifyingly, $480 \mathrm{~W}$ irradiation provided $93 \%$ of benzoic acid 3 (Table 1, entry 6). In a separate experiment, we measured the optical intensity of the light source. Although the short distance of $7 \mathrm{~cm}$ was too close to measure the optical densities of UV-LED when the space was $18 \mathrm{~cm}$, we could count them to be $51.6(120), 80.8(300)$, and $93.7(480) \mathrm{mW} / \mathrm{cm}^{2}(\mathrm{~V})$, respectively. Using these data, we estimated the optical intensities for $7 \mathrm{~cm}$ distance to be 350 (120), $535(300)$, and $638(480) \mathrm{mW} / \mathrm{cm}^{2}(\mathrm{~V})$, respectively, which were two orders of magnitude larger than $1.8 \mathrm{~mW} / \mathrm{cm}^{2}$ of $15 \mathrm{~W}$ blacklight, as measured with an aluminum foil wrapping. The temperatures of the reaction mixtures were $38^{\circ} \mathrm{C}$ (blacklight) and $60^{\circ} \mathrm{C}$ (UV-LED), which may have affected the solubility of oxygen in each case.

The relationship between irradiation power and reaction progress is summarized in Figure 3. Since recent work used a light wavelength of ca. $390 \mathrm{~nm}$ for decatungstateanion-catalyzed reactions [29-32]. We also tested other wavelengths of 385 and $395 \mathrm{~nm}$ for the irradiation of decatungstate catalyst and the reactions also proceeded well to give almost the same results compared as for irradiation at $365 \mathrm{~nm}$ (Table 1, entry 7 and 8). After 30 min of irradiation, benzaldehyde 2 was nearly consumed to give $92 \%$ of benzoic acid together with a small amount of benzaldehyde 2 (Table 1, entry 9). Compared with blacklight irradiation, the reaction period was shortened at least 20-fold via the use of the UV-LED system. When irradiation was stopped after $10 \mathrm{~min}$, benzaldehyde 2 was formed in $44 \%$ as the sole oxidation product with $54 \%$ of benzyl alcohol 1 remaining (Table 1, entry 10), which suggested that the oxidation leading to 3 proceeds stepwise via the initial formation of $\mathbf{2}$ [33]. In the open-air reaction or in the absence of a TBADT catalyst 
and under $480 \mathrm{~W}$ of irradiation for $1 \mathrm{~h}$, the reaction also proceeded and resulted in the formation of a mixture of benzaldehyde 2 (77\% and 36\%) and benzoic acid 3 (11\% and $25 \%$ ) (Table 1, entry 11 and 12). These results suggest that air also acts as an oxidant and a parallel non-catalytic mechanism exists to push the photo-oxidation of 1 [34-36]. We also examined the scalable photo-oxidation and $100 \mathrm{mg}(0.81 \mathrm{mmol}, 81 \%)$ of benzoic acid 3 was isolated after recrystallization (see Experimental 2.3).

Table 1. Oxidation of benzyl alcohol 1 by molecular oxygen with a catalytic amount of TBADT under photo-irradiation.

\begin{tabular}{|c|c|c|c|c|c|c|}
\hline $1(0.25 \mathrm{mmol})$ & \multicolumn{3}{|c|}{$\begin{array}{l}\text { blacklight }(15 \mathrm{~W}) \text { or UV-LED }(60-480 \mathrm{~W}) \\
{\left[(n-\mathrm{Bu})_{4} \mathrm{~N}\right]_{4} \mathrm{~W}_{10} \mathrm{O}_{32}(2 \mathrm{~mol} \%)} \\
\mathrm{O}_{2} \text { balloon }(1 \mathrm{~atm})\end{array}$} & \multicolumn{2}{|l|}{2} & 3 \\
\hline Entry & $\begin{array}{l}\text { Wavelength } \\
\text { (nm) }\end{array}$ & $\begin{array}{l}\text { Irradiation } \\
\text { Power (W) }\end{array}$ & $\begin{array}{l}\text { Time } \\
(\min )\end{array}$ & $1(\%)$ & $2(\%)$ & $3(\%)$ \\
\hline $1^{a}$ & 352 & 15 (blacklight) & 60 & 78 & 21 & 1 \\
\hline $2^{a}$ & 352 & 15 (blacklight) & 360 & 28 & 49 & 22 \\
\hline $3^{a}$ & 352 & 15 (blacklight) & 1200 & 0 & 3 & 97 \\
\hline 4 & 365 & 120 (UV-LED) & 60 & 7 & 38 & 54 \\
\hline 5 & 365 & 300 (UV-LED) & 60 & 0 & 31 & 69 \\
\hline 6 & 365 & 480 (UV-LED) & 10 & 15 & 18 & 67 \\
\hline 7 & 385 & 480 (UV-LED) & 10 & 13 & 18 & 69 \\
\hline 8 & 395 & 480 (UV-LED) & 10 & 20 & 24 & 56 \\
\hline 9 & 365 & 480 (UV-LED) & 30 & 0 & 7 & 92 \\
\hline 10 & 365 & 480 (UV-LED) & 60 & 0 & 6 & 93 \\
\hline $11^{b}$ & 365 & 480 (UV-LED) & 60 & 11 & 77 & 11 \\
\hline $12^{c}$ & 365 & 480 (UV-LED) & 60 & 39 & 36 & 25 \\
\hline
\end{tabular}

a Tube reactor and blacklight were wrapped with aluminum foil; ${ }^{\mathrm{b}}$ Air was used; ${ }^{\mathrm{c}}$ Without decatungstage catalyst.

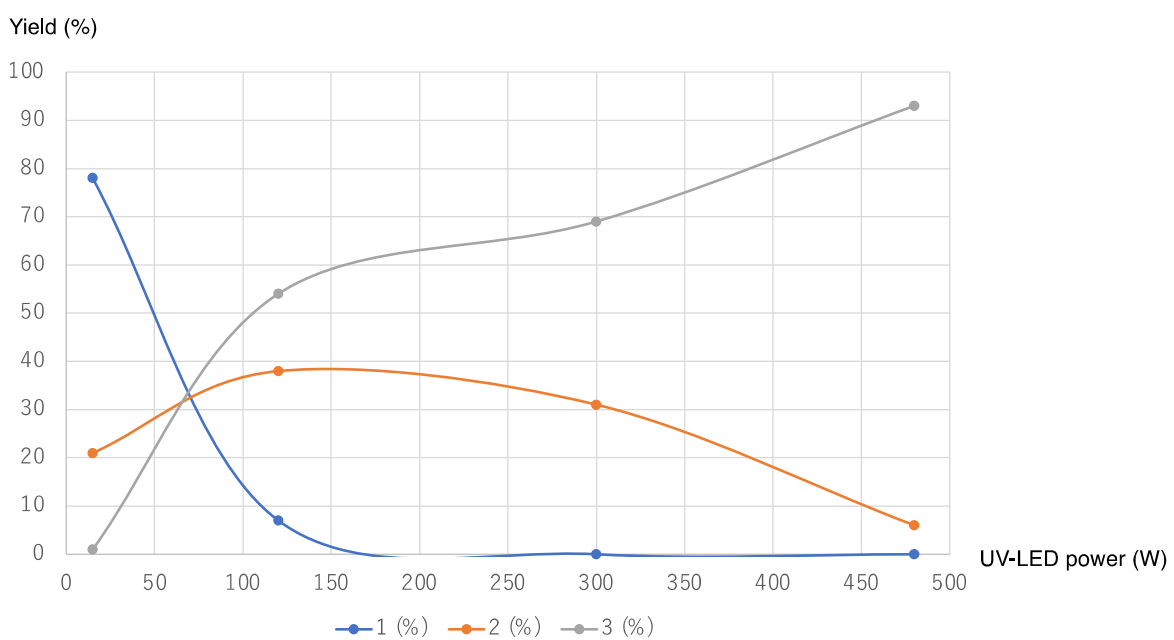

Figure 3. Effect of irradiation power for a $1 \mathrm{~h}$ reaction of 1 with $\mathrm{O}_{2}$.

To monitor the reaction quickly by NMR (60 MHz, Spinsolve, Magritek), we then examined this photoreaction using an NMR tube (Pyrex, diameter size: $5 \mathrm{~mm}$ ) as the reaction vessel. TBADT was added $(1.5 \mathrm{mg}, 2 \mathrm{~mol} \%)$ to a solution of acetonitrile- $\mathrm{d}_{3}(0.6 \mathrm{~mL})$ 
containing benzyl alcohol $1(0.02 \mathrm{mmol})$. Under an atmosphere of $\mathrm{O}_{2}$ gas, the $\mathrm{NMR}$ tube was irradiated with UV-LED light $(480 \mathrm{~W})$ at room temperature. With irradiation, the color of the solution immediately turned blue. We used ${ }^{1} \mathrm{H}$ NMR measurements at 3, 10, 30, and $60 \mathrm{~min}$ to monitor the reaction course (Figure 4) and the yields are plotted as a function of time in Figure 5.

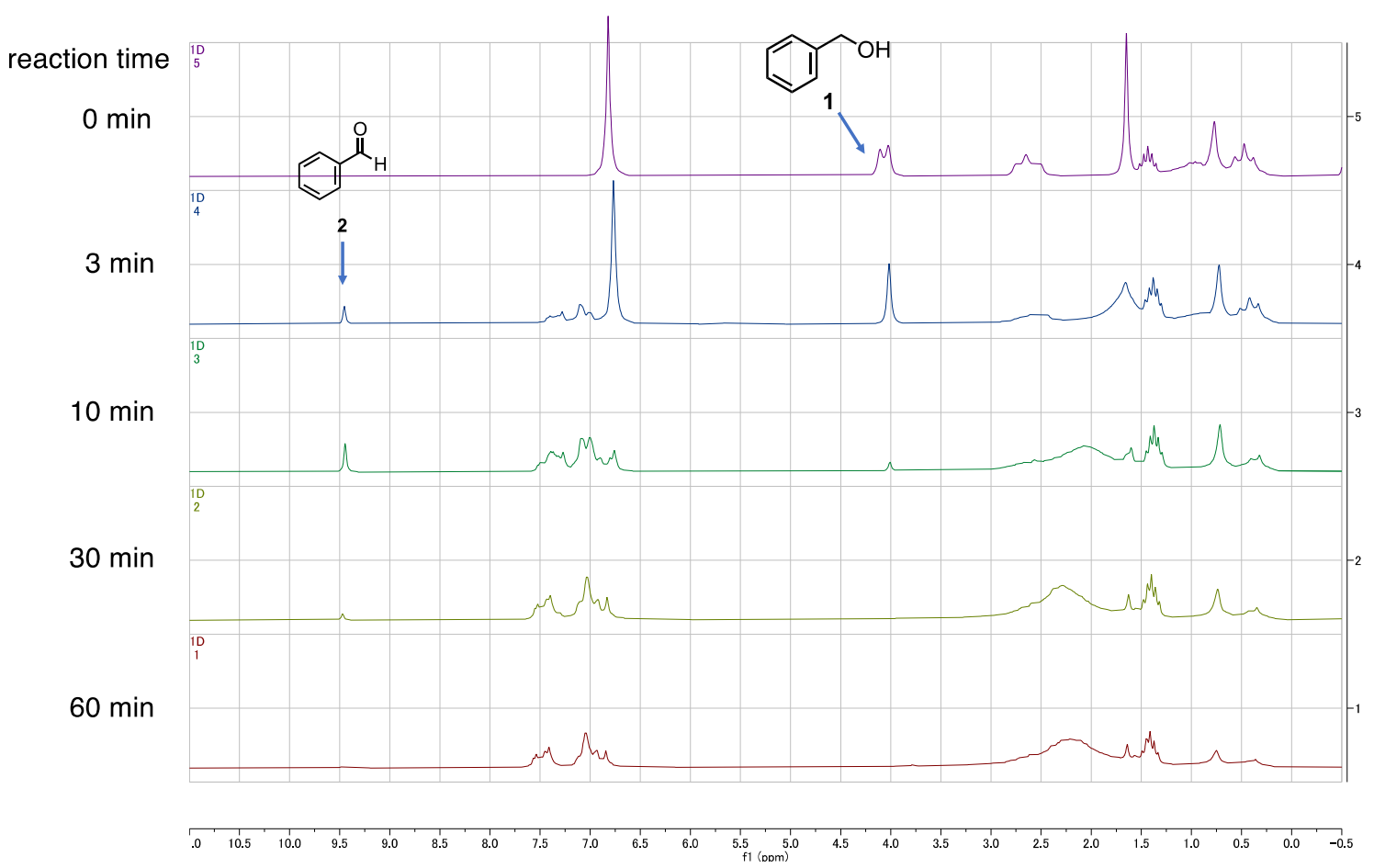

Figure 4. Stacked ${ }^{1} \mathrm{H}$ NMR spectra $(60 \mathrm{MHz})$ by time function.

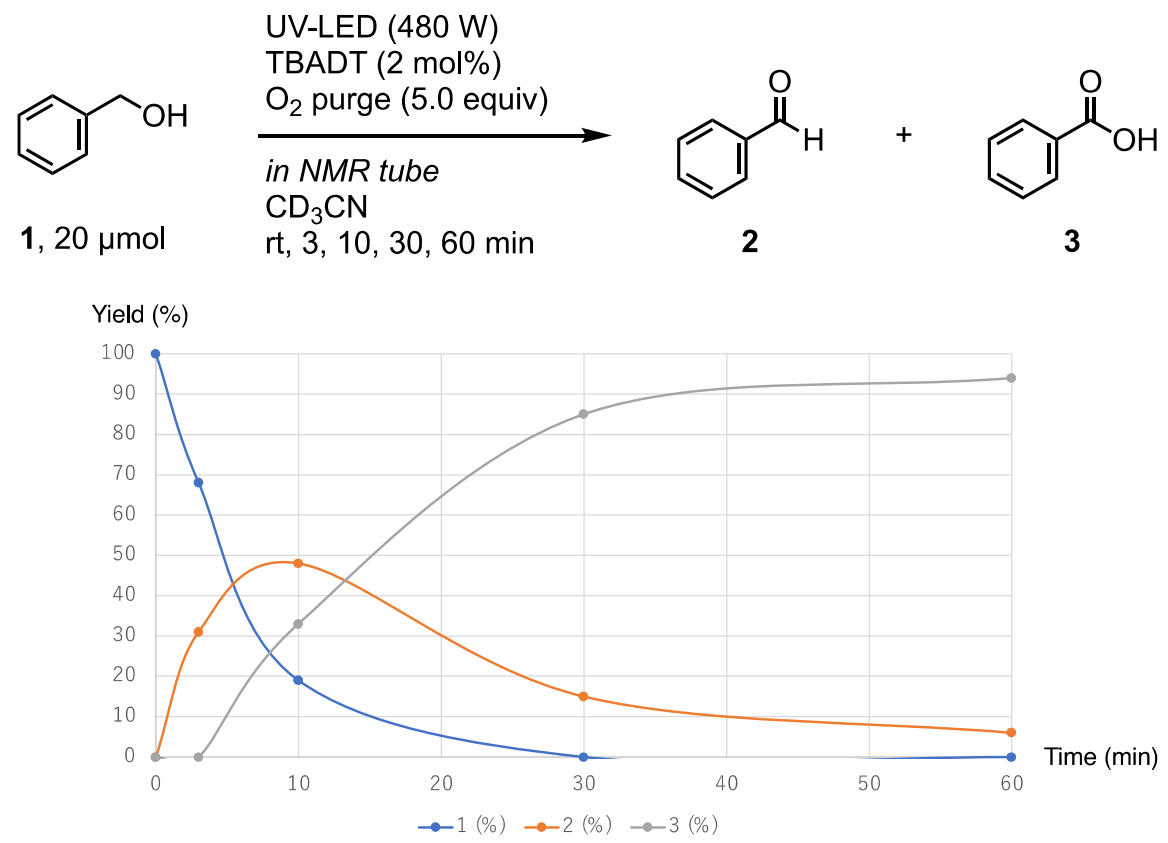

Figure 5. Time course for the oxidation of $\mathbf{1}$ to 2 and $\mathbf{3}$ via experiments using an NMR tube and irradiation by UV-LED at $480 \mathrm{~W}$. 
With the efficient conditions using high-power UV-LED irradiation established, finally we set out to examine a flow oxidation reaction [37]. Using a photo flow reactor (MiChS L-1 (channel sizes: width $=2 \mathrm{~mm}$, depth $=1 \mathrm{~mm}$, length $=3 \mathrm{~m}$, total volume $6 \mathrm{~mL}$ ), an acetonitrile solution of benzyl alcohol $(1,55 \mathrm{mM})$ and TBADT $(2 \mathrm{~mol} \%)$ was mixed with molecular oxygen (11 equiv) using a MiChS $\alpha 400$ mixer (T-shape mixer with $400 \mu \mathrm{m}$ inner diameter, supplied from MiChS, Inc.) and introduced into a microchannel of the photo flow reactor equipped with a back pressure regulator ( $5 \mathrm{psi}$ ). When irradiation using UV-LED $(480 \mathrm{~W})$ was carried out with a residence time of $5 \mathrm{~min}$, all benzyl alcohol was consumed and a mixture of $24 \%$ benzaldehyde and $71 \%$ benzoic acid was obtained (Scheme 2).

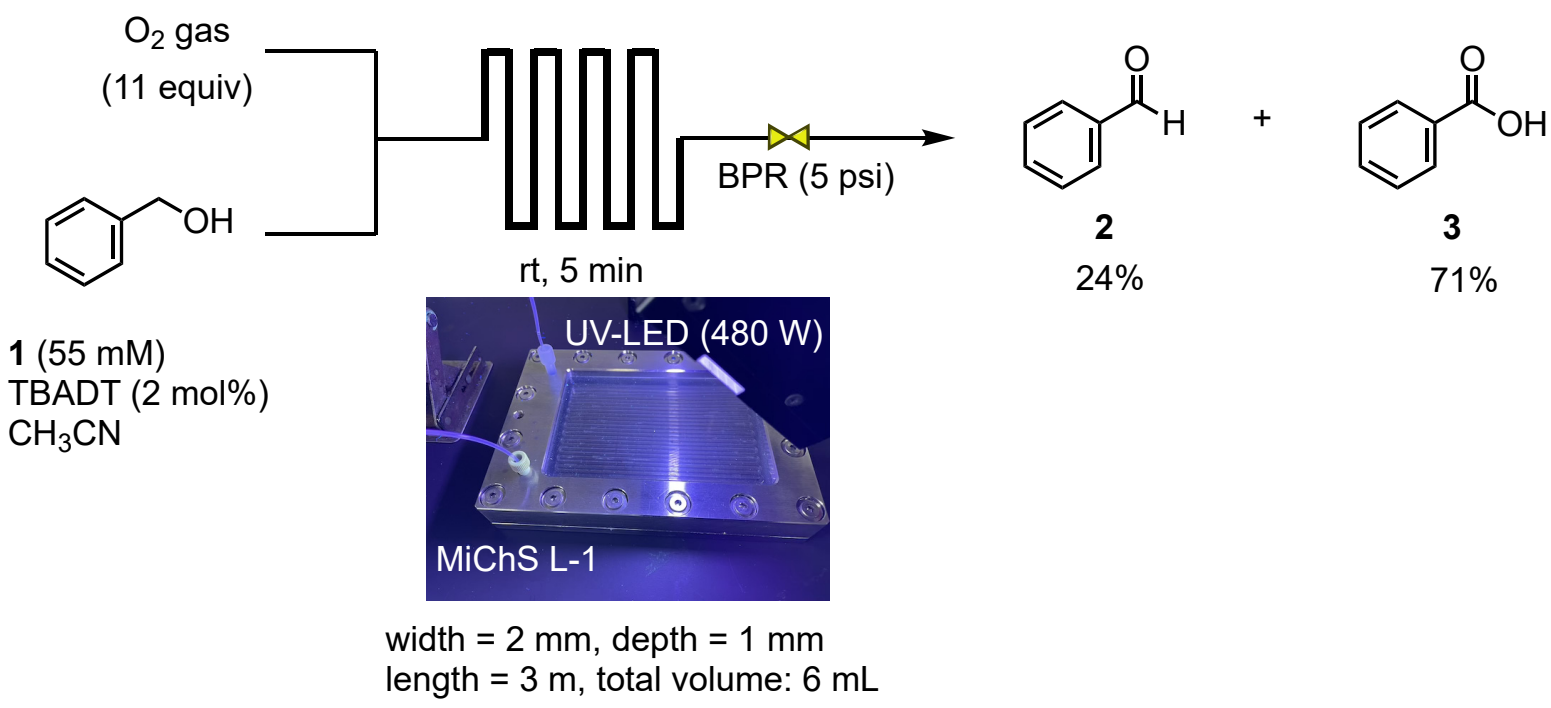

Scheme 2. Decatungstate-anion-catalyzed microflow oxidation of benzyl alcohol 1 using $\mathrm{O}_{2}$ and irradiation with UV-LED $(480 \mathrm{~W})$.

This study was focused on the acceleration of decatungstate-anion-catalyzed C-H functionalization via the oxidation of benzyl alcohol $\mathbf{1}$ with molecular oxygen as a model. Ultimately, the reaction was dramatically improved by the powerful irradiation of the light source [38]. On the contrary, the oxidation reaction of benzyl alcohol 1 using a $15 \mathrm{~W}$ blacklight irradiation ( $352 \mathrm{~nm}$ ) was very sluggish and gave a low yield of benzaldehyde 2 , despite the small reaction scale $(0.25 \mathrm{mmol})$. After $30 \mathrm{~min}$ of UV-LED $(365 \mathrm{~nm})$ irradiation at the maximum power of $480 \mathrm{~W}$, the reaction produced the desired benzoic acid 3 in high yield. These batch experiments were useful in the design of a continuous flow reaction system for these decatungstate-anion-catalyzed oxidation reactions. Indeed, by using a flow setup with a MiChS L-1 photo-flow reactor and the same exposure to a MiChS UV-LED-S photo-irradiation system, the oxidation reaction of benzyl alcohol 1 proceeded in $5 \mathrm{~min}$ of residence time to give benzoic acid 3 in a $71 \%$ yield. We believe that the combination of high-power irradiation and a thin flow reactor would be highly useful for the acceleration of decataungstate anion catalysis not only oxidation but also other reactions such as $\mathrm{C}-\mathrm{H}$ functionalization, and research along this line is now being actively pursued in our laboratory.

Author Contributions: Conceptualization was made by I.R. and T.F. Experimental was carried out by M.H., H.I. and T.K. Writing-original draft preparation was done by M.H., followed by editing by I.R. Funding acquisition was done by I.R. and T.F. All authors have read and agreed to the published version of the manuscript.

Funding: This work is supported by a project, JPNP14004, commissioned by the New Energy and Industrial Technology Development Organization (NEDO).

Conflicts of Interest: The authors declare no conflict of interest. 


\section{References}

1. Hill, C.L. Introduction of functionality into unactivated carbon-hydrogen bonds. Catalytic generation and nonconventional utilization of organic radicals. Synlett 1995, 1995, 127-132. [CrossRef]

2. Tzirakis, M.D.; Lykakis, I.N.; Orfanopoulos, M. Decatungstate as an efficient photocatalyst in organic chemistry. Chem. Soc. Rev. 2009, 38, 2609-2621. [CrossRef] [PubMed]

3. Protti, S.; Fagnoni, M.; Ravelli, D. Photocatalytic C-H activation by hydrogen-atom transfer in synthesis. ChemCatChem 2015, 7, 1516-1523. [CrossRef]

4. Ravelli, D.; Protti, S.; Fagnoni, M. Decatungstate anion for photocatalyzed "window ledge" reactions. Acc. Chem. Res. 2016, 49, 2232-2242. [CrossRef]

5. Ravelli, D.; Fagnoni, M.; Fukuyama, T.; Nishikawa, T.; Ryu, I. Site-selective C-H functionalization by decatungstate anion photocatalysis: Synergistic control by polar and steric effects expands the reaction scope. ACS Catal. 2018, 8, 701-713. [CrossRef]

6. Zakrzewski, J.; Giannotti, C. Photo-oxygenation of 1,8-cineole by molecular oxygen catalysed by $\left(\mathrm{Bu}_{4} \mathrm{~N}_{4} \mathrm{~W}_{10} \mathrm{O}_{32}\right.$. J. Photochem. Photobiol. A Chem. 1992, 63, 173-177. [CrossRef]

7. Lykakis, I.N.; Tanielian, C.; Orfanopoulos, M. Decatungstate photocatalyzed oxidation of aryl alkanols. electron transfer or hydrogen abstraction mechanism? Org. Lett. 2003, 5, 2875-2878. [CrossRef]

8. Maldotti, A.; Amadelli, R.; Vitali, I.; Borgatti, L.; Molinari, A. $\mathrm{CH}_{2} \mathrm{Cl}_{2}$-assisted functionalization of cycloalkenes by photoexcited $\left(n \mathrm{Bu}_{4} \mathrm{~N}\right)_{4} \mathrm{~W}_{10} \mathrm{O}_{32}$ heterogenized on $\mathrm{SiO}_{2}$. J. Mol. Catal. A Chem. 2003, 204-205, 703-711. [CrossRef]

9. Lykakis, I.N.; Orfanopoulos, M. Photooxidation of aryl alkanes by a decatungstate/triethylsilane system in the presence of molecular oxygen. Tetrahedron Lett. 2004, 45, 7645-7649. [CrossRef]

10. Tzirakis, M.D.; Lykakis, I.N.; Panagiotou, G.D.; Bourikas, K.; Lycourghiotis, A.L.; Kordulis, C.; Orfanopoulos, M. Decatungstate catalyst supported on silica and $\gamma$-alumina: Efficient photocatalytic oxidation of benzyl alcohols. J. Catal. 2007, 252, 178-189. [CrossRef]

11. Laudadio, G.; Govaerts, S.; Wang, Y.; Ravelli, D.; Koolman, H.F.; Fagnoni, M.; Djuric, S.W.; Noel, T. Selective C(sp ${ }^{3}$ )-H aerobic oxidation enabled by decatungstate photocatalysis in flow. Angew. Chem. Int. Ed. 2018, 57, 4078-4082. [CrossRef] [PubMed]

12. Yamase, T.; Usami, Y. Photocatalytic dimerization of olefins by decatungstate, $\left[\mathrm{W}_{10} \mathrm{O}_{32}\right]^{4-}$, in acetonitrile and magnetic resonance studies of photoreduced species. J. Chem. Soc. Dalton Trans. 1998, 183-190.

13. Fukuyama, T.; Nishikawa, T.; Ryu, I. Site-Selective $\mathrm{C}\left(\mathrm{sp}^{3}\right)-\mathrm{H}$ functionalization of fluorinated alkanes driven by polar effects using a tungstate photocatalyst. Eur. J. Org. Chem. 2020, 2020, 1424-1428. [CrossRef]

14. Bonassi, F.; Ravelli, D.; Protti, S.; Fagnoni, M. Decatungstate photocatalyzed acylations and alkylations in flow via hydrogen atom transfer. Adv. Synth. Catal. 2015, 357, 3687-3695. [CrossRef]

15. Schultz, D.M.; Levesque, F.; DiRocco, D.A.; Reibarkh, M.; Ji, Y.; Joyce, L.A.; Dropinski, J.F.; Sheng, H.; Sherry, B.D.; Davies, I.W. Oxyfunctionalization of the remote $\mathrm{C}-\mathrm{H}$ bonds of aliphatic amines by decatungstate photocatalysis. Angew. Chem. Int. Ed. 2017, 56, 15274-15278. [CrossRef] [PubMed]

16. Laudadio, G.; Deng, Y.; van del Wal, K.; Ravelli, D.; Nuno, M.; Fagnoni, M.; Guthrie, D.; Sun, Y.; Noel, T. C(sp $\left.{ }^{3}\right)-H$ functionalizations of light hydrocarbons using decatungstate photocatalysis in flow. Science 2020, 369, 92-96. [CrossRef]

17. Bonciolini, S.; Filippo, M.D.; Baumann, M. A scalable continuous photochemical process for the generation of aminopropylsulfones. Org. Biomol. Chem. 2020, 18, 9428-9432. [CrossRef]

18. Renneke, R.F.; Pasquali, M.; Hill, C.L. Polyoxometalate systems for the catalytic selective production of nonthermodynamic alkenes from alkanes. Nature of excited-state deactivation processes and control of subsequent thermal processes in polyoxometalate photoredox chemistry. J. Am. Chem. Soc. 1990, 112, 6585-6594. [CrossRef]

19. Bahamonde, A.; Murphy, J.J.; Savarese, M.; Bremond, E.; Cavalli, A.; Melchiorre, P. Studies on the enantioselective iminium ion trapping of radicals triggerd by an electron-relay mechanism. J. Am. Chem. Soc. 2017, 139, 4559-4567. [CrossRef]

20. Wen, Z.; Maheshwari, A.; Sambiagio, C.; Deng, Y.; Laudadio, G.; Aken, K.V.; Sun, Y.; Gemoets, H.P.L.; Noel, T. Optimization of a decatungstate-catalyzed $\mathrm{C}\left(\mathrm{sp}^{3}\right)-\mathrm{H}$ alkylation using a continuous oscillatory milli structured photoreactor. Org. Process Res. Dev. 2020, 24, 2356-2361. [CrossRef] [PubMed]

21. Fukuyama, T.; Rahman, M.T.; Sato, M.; Ryu, I. Adventures in inner space: Microflow synthesis for practical organic synthesis. Synlett 2008, 2008, 151-163.

22. Voyle, E.E.; Oelgemöller, M. Micro-photochemistry: Photochemistry in microstructured reactors. The new photochemistry of the future? Photochem. Photobiol. Sci. 2008, 7, 1313-1322.

23. Cambie, D.; Bottecchia, C.; Straathof, N.J.W.; Hessel, V.; Noel, T. Applications of continuous-flow photochemistry in organic synthesis, material science, and water treatment. Chem. Rev. 2016, 116, 10276-10341. [CrossRef]

24. Hone, C.A.; Kappe, C.O. The use of molecular oxygen for liquid phase aerobic oxidations in continuous flow. Top. Curr. Chem. 2019, 377, 2. [CrossRef] [PubMed]

25. Gambacorta, G.; Sharley, J.S.; Baxendale, I.R. A comprehensive review of flow chemistry techniques tailored to the flavours and fragrances industries. Beilstein J. Org. Chem. 2021, 17, 1181-1312. [CrossRef] [PubMed]

26. Morimoto, Y.; Park, J.; Suenobu, T.; Lee, Y.-M.; Nam, W.; Fukuzumi, S. Mechanistic borderline of one-step hydrogen atom transfer versus stepwise $\mathrm{Sc}^{3+}$-coupled electron transfer from benzyl alcohol derivatives to a non-heme iron(IV)-oxo complex. Inorg. Chem. 2012, 51, 10025-10036. [CrossRef] [PubMed] 
27. Xie, J.; Lo, P.-K.; Lam, K.-C.; Lau, T.-C. A hydrogen-atom transfer mechanism in the oxidation of alcohols by $\left[\mathrm{FeO}_{4}\right]^{2-}$ in aqueous solution. Dalton Trans. 2018, 47, 240-245. [CrossRef] [PubMed]

28. Kushch, O.V.; Hordieieva, I.O.; Kompanets, M.O.; Zosenko, O.O.; Opedia, I.A.; Shendrik, A.N. Hydrogen atom transfer from benzyl alcohol to N-oxyl radicals. Reactivity parameters. J. Org. Chem. 2021, 86, 3797-3799. [CrossRef]

29. Fan, P.; Zhang, C.; Lan, Z.; Lin, Z.; Zhang, L.; Wang, C. Photocatalytic hydroacylation of trifluoromethyl alkenes. Chem. Commun. 2019, 55, 12691-12694. [CrossRef]

30. Kuang, Y.; Cao, H.; Junhong, H.; Chew, J.; Chen, W.; Shi, X.; Wu, J. Visible light driven deuteration of formyl C-H and hydridic $\mathrm{C}\left(\mathrm{sp}^{3}\right)-\mathrm{H}$ bonds in feedstock chemicals and pharmaceutical molecules. Chem. Sci. 2020, 11, 8912-8918. [CrossRef]

31. Xu, S.; Chen, H.; Zhou, Z.; Kong, W. Three-component alkene difunctionalization by direct and selective activation of aliphatic C-H bonds. Angew. Chem. Int. Ed. 2021, 60, 7405-7411. [CrossRef] [PubMed]

32. Murugesan, V.; Ganguly, A.; Karthika, A.; Rasappan, R. C-H alkylation of aldehydes by merging TBADT hydrogen atom transfer with nickel catalysis. Org. Lett. 2021, 23, 5389-5393. [CrossRef] [PubMed]

33. Sankar, M.; Nowicka, E.; Carter, E.; Murphy, D.M.; Knight, D.W.; Bethell, D.; Hutchings, G.J. The benzaldehyde oxidation paradox explained by the interception of peroxy radical by benzyl alcohol. Nat. Commun. 2014, 5, 3332. [CrossRef]

34. Feng, W.; Wu, G.; Li, L.; Guan, N. Solvent-free selective photocatalytic oxidation of benzyl alcohol over modified TiO 2 . Green Chem. 2011, 13, 3265-3272. [CrossRef]

35. Shimada, Y.; Hattori, K.; Tada, N.; Miura, T.; Itoh, A. Facile aerobic photooxidation of alcohols using 2-chloroanthraquinone visible light irradiation. Synthesis 2013, 45, 2684-2690.

36. Nikitas, N.F.; Tzaras, D.I.; Triandafillidi, I.; Kokotos, C.G. Photochemical oxidation of benzylic primary and secondary alcohols utilizing air as the oxidant. Green Chem. 2020, 22, 471-477. [CrossRef]

37. Nagasawa, Y.; Tanba, K.; Tada, N.; Yamaguchi, E.; Itoh, A. A Study of aerobic photooxidation with a continuous flow microreactor. Synlett 2015, 26, 412-415.

38. Tanielian, C. Decatungstate photocatalysis. Coord. Chem. Rev. 1998, 178-180, 1165-1181. [CrossRef] 